\title{
Novel Etiological and Therapeutic Strategies for Neurodiseases: RNA Editing Enzyme Abnormality in Sporadic Amyotrophic Lateral Sclerosis
}

\author{
Takuto Hideyama ${ }^{1, * a}$, Takenari Yamashita ${ }^{1}$, Yoshinori Nishimoto ${ }^{2}$, Takeshi Suzuki ${ }^{3}$, and Shin Kwak ${ }^{1, * b}$ \\ ${ }^{\prime}$ Department of Neurology, Graduate School of Medicine, The University of Tokyo, \\ 7-3-1 Hongo, Bunkyo-ku, Tokyo 113-8655, Japan \\ ${ }^{2}$ Deptartment of Neurology, School of Medicine, Keio University, 35 Shinanomati, Shinjuku-ku, Tokyo 160-8582, Japan \\ ${ }^{3}$ Division of Basic Biological Sciences, Faculty of Pharmacy, Keio University, \\ 1-5-30 Shibakoen, Minato-ku, Tokyo 105-8512, Japan
}

Received October 20, 2009; Accepted March 5, 2010

\begin{abstract}
The motor neurons of patients with sporadic amyotrophic lateral sclerosis (ALS) express abundant Q/R site-unedited GluR2 mRNA, whereas those of patients with other motor neuron diseases including familial ALS associated with mutated SOD1 (ALS1) and those of normal subjects express only $\mathrm{Q} / \mathrm{R}$ site-edited GluR2 mRNA. Because adenosine deaminase acting on RNA type 2 (ADAR2) specifically catalyzes GluR2 Q/R site-editing, it is likely that ADAR2 activity is not sufficient to edit this site completely in motor neurons of patients with sporadic ALS. Because these molecular abnormalities occur in disease- and motor neuron-specific fashion and induce fatal epilepsy in mice, we have hypothesized that GluR2 Q/R site-underediting due to ADAR2 underactivity is a cause of neuronal death in sporadic ALS. We found that cytoplasmic fragile X mental retardation protein interacting protein 2 (CYFIP2) mRNA had an ADAR2-mediated editing position using RNA interference knockdown. Our review will include a discussion of new ADAR2 substrates that may be useful for research on sporadic ALS.
\end{abstract}

Keywords: RNA editing, amyotrophic lateral sclerosis (ALS), $\alpha$-amino-3-hydroxy-5-methyl-4-isoxazolepropionate (AMPA) receptor, GluR2 Q/R, cytoplasmic fragile $\mathrm{X}$ mental retardation protein interacting protein 2 (CYFIP2), neurodisease

\section{Introduction}

Amyotrophic lateral sclerosis (ALS) is a neurodegenerative disease characterized by progressive paralysis with muscle wasting due to selective loss of upper and lower motor neurons. More than $90 \%$ of cases of ALS are sporadic, while the remaining cases of ALS have more than one other affected family member (familial ALS). Gene mutations causative of familial ALS, including those of the superoxide dismutase 1 (SOD1) gene, have not been detected in the majority of sporadic cases

Corresponding authors

*ahideyamat-int@h.u-tokyo.ac.jp, *bkwak-tky@umin.net Published online in J-STAGE on April 16, 2010 (in advance) doi: 10.1254/jphs.09R21FM of ALS (1), indicating that the pathogenesis of sporadic ALS differs from that of familial ALS. Several hypotheses concerning the pathogenesis of sporadic ALS have been suggested, including those related to excitotoxicity (2), toxicity (3), autoimmunity (4), infection (5), and oxidative stress (6). Among these, considerable evidence supports the excitotoxic hypothesis $(7-9)$.

The mechanism of initiation of motor neuronal death appears to involve excessive influx of $\mathrm{Ca}^{2+}$ through $\alpha$ amino-3-hydroxy-5-methyl-4-isoxazolepropionate (AMPA) receptors (10). The determinants of this $\mathrm{Ca}^{2+}$ influx include the $\mathrm{Ca}^{2+}$ permeability of AMPA receptors, which is due to the presence of the GluR2 subunit and related to the reduction of GluR2 Q/R site-editing, and the density of receptors on the cell surface, which is regulated by many factors including regulatory proteins, direct 
phosphorylation, and RNA editing at the GluR2 Q/R site (Fig. 1) (11).

We have demonstrated that RNA editing of GluR2, a subunit of the AMPA receptor, at the $\mathrm{Q} / \mathrm{R}$ site is decreased in motor neurons of a small number of sporadic ALS cases in disease-specific and neuronal class-selective fashion $(12,13)$. Functional AMPA receptors are tetrameric assemblies of GluR1, GluR2, GluR3, and GluR4, in various combinations produced in nonstochastic fashion. In mammals, all GluR2 mRNAs in neurons are completely edited and the majority of AMPA receptors have GluR2 in their composition, making AMPA receptors $\mathrm{Ca}^{2+}$-impermeable. In the motor neurons in patients with ALS, due to underediting of GluR2 mRNA at the $\mathrm{Q} / \mathrm{R}$ site, the proportion of $\mathrm{Ca}^{2+}$-permeable AMPA receptors may be increased, resulting in neuronal death (14) . RNA editing at the GluR2 Q/R site is specifically catalyzed by ADAR2 (15). Reduction of this enzyme activity is probably the cause of the underediting observed in ALS motor neurons.

\section{RNA editing and ADARs}

RNA editing is a posttranscriptional modification of mRNA that alters the amino acids specified by the gene. The resulting change in amino acid residues alters the biological function of translated molecules; this is most clearly demonstrated in alterations of channel properties including those of the $\mathrm{Ca}^{2+}$ permeability of GluRs, a subunit of AMPA, and kainate receptors $(16,17)$. In human and rodent brains, the efficiency of editing at each editing site of GluRs is developmentally and regionally regulated (18-24), and abnormal RNA editing may result in animal or human diseases affecting the central nervous system. However, no consistent findings have been reported regarding alteration of these editing sites in the case of temporal lobe epilepsy (25), depression (26), and schizophrenia (27). In contrast, abnormal editing has been demonstrated to be associated with certain neurological diseases including amyotrophic lateral sclerosis $(28,29)$.

These alterations are catalyzed by the adenosine deaminases, which recognize a specific target sequence of nucleotides and convert an adenosine (A) to an inosine (I), which the ribosome translates as a guanosine $(\mathrm{G})$.

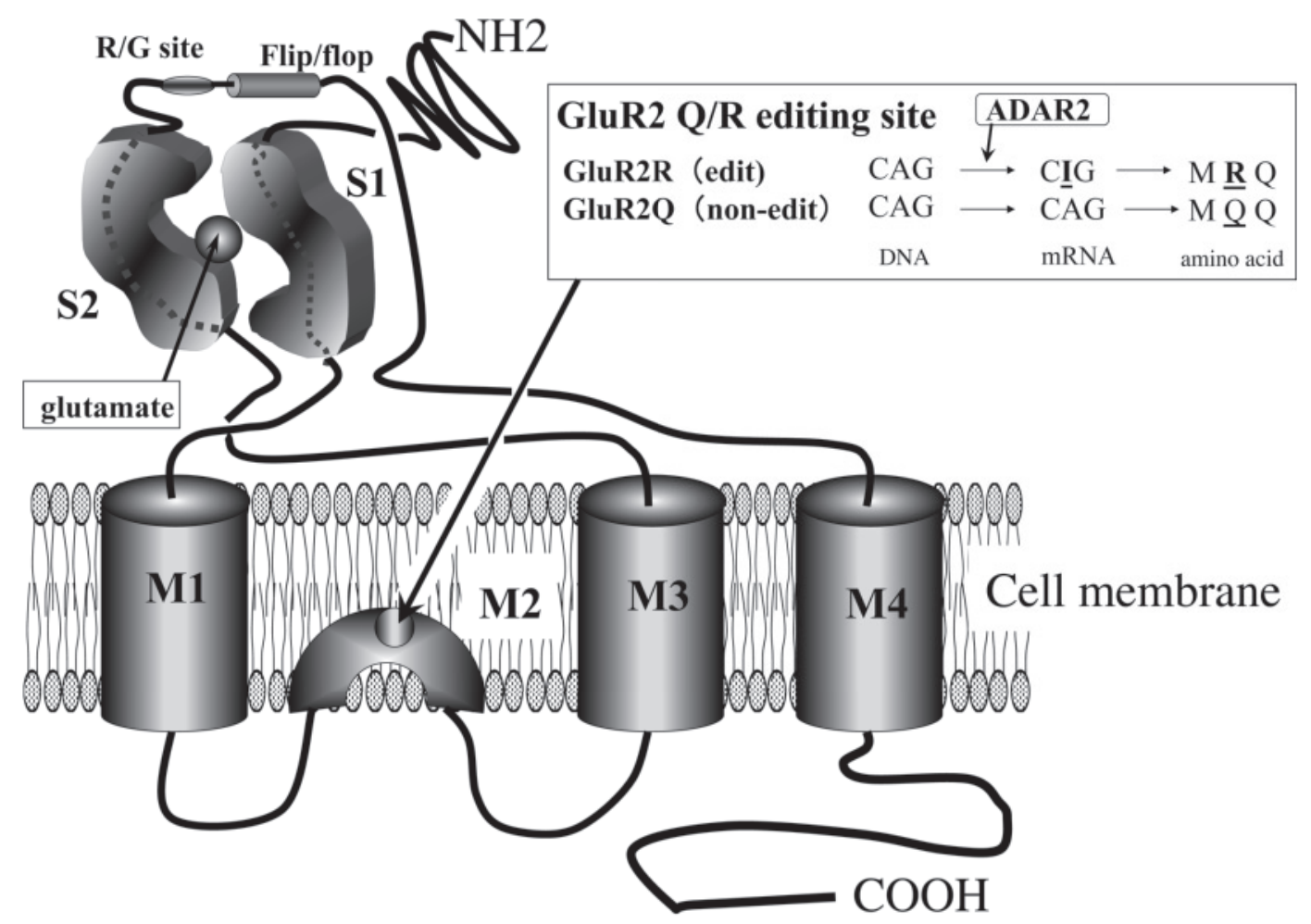

Fig. 1. Structure of the GluR subunit. GluR2 subunit has four membrane domains (M1 - M4). The Q/R site (Q/R) is located in the M2 domain and this editing site is the determinant of $\mathrm{Ca}^{2+}$ permeability of the AMPA receptor. The R/G site (R/G) and the flip/ flop alternative splicing site are located between the M3 and M4 domains, and these sites are the determinants of channel desensitization. 
This A-to-I RNA editing controls a variety of biologically important mRNAs and is specifically catalyzed by either adenosine deaminase acting on RNA type 1 (ADAR1) or type 2 (ADAR2) in mammals including humans. A lot of novel A-to-I editing sites have been identified in vitro in mRNAs abundantly expressed in mammalian organs by means of computational genomic techniques (30), although the enzyme catalyzing editing at these sites has yet to be determined.

ADAR2 predominantly catalyzes RNA editing at the $\mathrm{Q} / \mathrm{R}$ site of GluR2 both in vivo and in vitro $(15,31,32)$, whereas both ADAR1 and ADAR2 catalyze the Q/R sites of GluR5 and GluR6, which are subunits of kainate receptors $(15,32)$. ADAR3, a third member of the ADAR family, is exclusively expressed in the central nervous system but is catalytically inactive on both extended dsRNA and known pre-mRNA editing substrates (33, 34).

\section{New substrates of ADAR2}

Using immunoprecipitation and the RNA interference (RNAi) knockdown system in vitro, we investigated whether the recently reported A-to-I editing sites in CYFIP2, filamin A (FLNA), bladder cancer associated protein (BLCAP), and insulin-like growth factor binding protein 7 (IGFBP7) mRNAs (35) are the substrates of ADAR1 or ADAR2 in humans. We also examined whether these mRNAs form complexes with ADAR2 in humans, by means of ADAR2-immunoprecipitation of nuclear extracts of human cerebellum (36).

Using RNAi knockdown, we found that CYFIP2 mRNA had an ADAR2-mediated editing position and that BLCAP mRNA had an ADAR1-mediated editing position (Table 1) $(36,37)$. In addition, we found that ADAR2 formed complexes with mRNAs with ADAR2mediated editing positions including GluR2, kv1.1, and CYFIP2 mRNAs, particularly when the editing sites were edited in human cerebellum by means of the immunoprecipitation method. CYFIP2 mRNA was ubiquitously expressed in human tissues with variable extents of K/E site-editing (Fig. 2) (36, 37).

Table 1. Novel A-to-I positions

\begin{tabular}{lccc}
\hline Editing site & CYFIP2 K/E & BLCAP Y/C & Reference \\
\hline Normal mouse brain (\%) & 90 & 50 & $(38)$ \\
Mouse neuronal primary culture (\%) & 54.5 & 36.5 & $(38)$ \\
ADAR $^{-/}$mouse neuronal primary culture (\%) & 50 & 8.5 & $(38)$ \\
ADAR2 $^{-/-}$mouse brain (\%) & approx. 11 & 33.5 & $(38)$ \\
Human cerebellum (\%) & 84 & approx. 30 & $(37)$ \\
Hela cell (\%) & 1.9 & 13 & $(37)$ \\
ADAR1 siRNA in Hela cell (\%) & $0.4-1.1$ & 0 & $(37)$ \\
ADAR2 siRNA in Hela cell (\%) & 0 & $16-18$ & $(37)$ \\
\hline
\end{tabular}

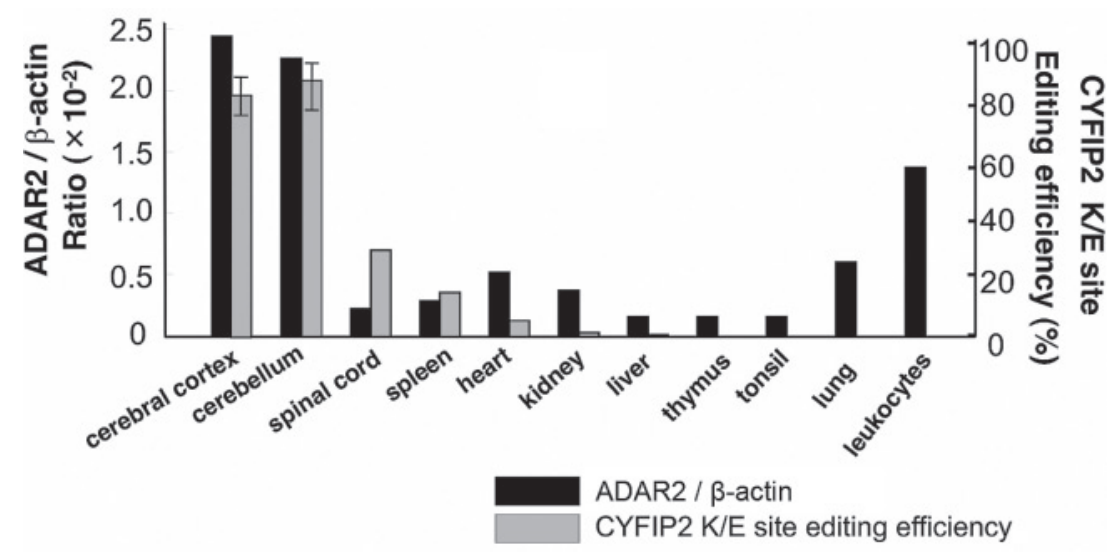

Fig. 2. Extent of CYFIP2-mRNA editing and level of expression of ADAR2 mRNA in human tissues. Tissues with high expression levels of ADAR 2 mRNA in the $\beta$-actin mRNA base (black columns) tend to show higher extent of RNA editing at the CYFIP2 $\mathrm{K} / \mathrm{E}$ site (gray columns) than those with low ADAR2 mRNA expression level, whereas some regions with high ADAR2 mRNA expression level (e.g., leukocytes) showed very low extents of CYFIP2 mRNA editing. Value represents the mean \pm S.D. for multiple samples of cerebral cortex $(n=4)$, cerebellum $(n=5)$, and leukocytes $(n=7)$ and represents the mean for the rest of tissue samples $(\mathrm{n}<3)$. Reproduced from Ref. 37 with permission. 


\section{Conclusion}

CYFIP2 mRNA is particularly abundant in the central nervous system including motor neurons in the spinal cord, and the extent of site-editing in it ranges from $30 \%$ to $85 \%$ in the human central nervous system $(37,38)$. Because ADAR2 underactivity may be a cause of death of motor neurons in sporadic ALS, the CYFIP2 K/E site, a newly identified ADAR2-mediated editing position, may become a useful tool for ALS research. To investigate whether deficiency of ADAR2 activity induces slow neuronal death as seen in motor neurons of sporadic ALS patients, we have generated genetically modified mice in which the ADAR2 gene is conditionally knocked out in motor neurons using the Cre-loxP system.

\section{Acknowledgments}

This study was supported in part by a Grant-in-Aid for Scientific Research from the Ministry of Health, Labor, and Welfare of Japan (H18-Kokoro-017, SK); from the Ministry of Education, Culture, Sports, Science, and Technology of Japan (18023012, SK); a grant from The Nakabayashi Trust for ALS Research (TH); and a grant from the Japan ALS association (TH).

\section{References}

1 Jackson M, Al-Chalabi A, Enayat ZE, Chioza B, Leigh PN, Morrison KE. Copper/zinc superoxide dismutase 1 and sporadic amyotrophic lateral sclerosis: analysis of 155 cases and identification of a novel insertion mutation. Ann Neurol. 1997;42:803807.

2 Rothstein J, Tsai G, Kuncl R, Clawson L, Cornblath D, Drachman $\mathrm{D}$, et al. Abnormal excitatory amino acid metabolism in amyotrophic lateral sclerosis. Ann Neurol. 1990;28:18-25.

3 Durlach J, Bac P, Durlach V, Durlach A, Bara M, Guiet-Bara A. Are age-related neurodegenerative diseases linked with various types of magnesium depletion? Magnes Res. 1997;10:339-353.

4 Hoffman PM, Robbins DS, Oldstone MB, Gibbs CJ Jr, Gajdusek DC. Humoral immunity in Guamanians with amyotrophic lateral sclerosis and parkinsonism-dementia. Ann Neurol. 1981;10:193196.

5 Moulignier A, Moulonguet A, Pialoux G, Rozenbaum W. Reversible ALS-like disorder in HIV infection. Neurology. 2001;57:9951001.

6 Rao AV, Balachandran B. Role of oxidative stress and antioxidants in neurodegenerative diseases. Nutr Neurosci. 2002;5:291309.

7 Allaoua H, Chaudieu I, Krieger C, Boksa P, Privat A, Quirion R. Alterations in spinal cord excitatory amino acid receptors in amyotrophic lateral sclerosis patients. Brain Res. 1992;579:169172.

8 Vandenberghe W, Robberecht W, Brorson J. AMPA receptor calcium permeability, GluR2 expression, and selective motoneuron vulnerability. J Neurosci. 2000;20:123-132.

9 Rothstein JD, Kuncl RW. Neuroprotective strategies in a model of chronic glutamate-mediated motor neuron toxicity. J Neurochem. 1995;65:643-651.
10 Kwak S, Weiss JH. Calcium-permeable AMPA channels in neurodegenerative disease and ischemia. Curr Opin Neurobiol. 2006; 16:281-287.

11 Kawahara Y, Kwak S. Excitotoxicity and ALS: what is unique about the AMPA receptors expressed on spinal motor neurons? Amyotroph Lateral Scler Other Motor Neuron Disord. 2005;6: 131-144.

12 Takuma H, Kwak S, Yoshizawa T, Kanazawa I. Reduction of GluR2 RNA editing, a molecular change that increases calcium influx through AMPA receptors, selective in the spinal ventral gray of patients with amyotrophic lateral sclerosis. Ann Neurol. 1999;46:806-815.

13 Kawahara Y, Ito K, Sun H, Aizawa H, Kanazawa I, Kwak S. Glutamate receptors: RNA editing and death of motor neurons. Nature. 2004;427:801.

14 Kwak S, Kawahara Y. Deficient RNA editing of GluR2 and neuronal death in amyotropic lateral sclerosis. J Mol Med. 2005;83: 110-120.

15 Higuchi M, Maas S, Single F, Hartner J, Rozov A, Burnashev N, et al. Point mutation in an AMPA receptor gene rescues lethality in mice deficient in the RNA-editing enzyme ADAR2. Nature. 2000;406:78-81.

16 Burnashev N, Monyer H, Seeburg P, Sakmann B. Divalent ion permeability of AMPA receptor channels is dominated by the edited form of a single subunit. Neuron. 1992;8:189-198.

17 Köhler M, Burnashev N, Sakmann B, Seeburg P. Determinants of $\mathrm{Ca}^{2+}$ permeability in both TM1 and TM2 of high affinity kainate receptor channels: diversity by RNA editing. Neuron. 1993; 10:491-500.

18 Paschen W, Djuricic B. Extent of RNA editing of glutamate receptor subunit GluR5 in different brain regions of the rat. Cell Mol Neurobiol. 1994;14:259-270.

19 Paschen W, Schmitt J, Dux E, Djuricic B. Temporal analysis of the upregulation of GluR5 mRNA editing with age: regional evaluation. Brain Res Dev Brain Res. 1995;86:359-363.

20 Paschen W, Djuricic B. Regional differences in the extent of RNA editing of the glutamate receptor subunits GluR2 and GluR6 in rat brain. J Neurosci Methods. 1995;56:21-29.

21 Schmitt J, Dux E. Gissel C, Paschen W. Regional analysis of developmental changes in the extent of GluR6 mRNA editing in rat brain. Brain Res DevelopBrain Res. 1996;91:153-157.

22 Bernard A, Ferhat L, Dessi F, Charton G, Represa A, Ben-Ari Y, et al. Q/R editing of the rat GluR5 and GluR6 kainate receptors in vivo and in vitro: evidence for independent developmental, pathological and cellular regulation. Eur J Neurosci. 1999;11:604 616.

23 Kawahara Y, Ito K, Sun H, Kanazawa I, Kwak S. Low editing efficiency of GluR2 mRNA is associated with a low relative abundance of ADAR2 mRNA in white matter of normal human brain. Eur J Neurosci. 2003;18:23-33.

24 Barbon A, Vallini I, La Via L, Marchina E, Barlati S. Glutamate receptor RNA editing: a molecular analysis of GluR2, GluR5 and GluR6 in human brain tissues and in NT2 cells following in vitro neural differentiation. Brain Res Mol Brain Res. 2003;117:168178.

25 Kortenbruck G, Berger E, Speckmann EJ, Musshoff U. RNA editing at the Q/R site for the glutamate receptor subunits GLUR2, GLUR5, and GLUR6 in hippocampus and temporal cortex from epileptic patients. Neurobiol Dis. 2001;8:459-468.

26 Englander MT, Dulawa SC, Bhansali P, Schmauss C. How stress 
and fluoxetine modulate serotonin $2 \mathrm{C}$ receptor pre-mRNA editing. J Neurosci 2005;25:648-651.

27 Iwamoto K, Bundo M, Kato T. Estimating RNA editing efficiency of five editing sites in the serotonin $2 \mathrm{C}$ receptor by pyrosequencing. Rna 2005; 11:1596-1603.

28 Takuma H, Kwak S, Yoshizawa T, Kanazawa I. Reduction of GluR2 RNA editing, a molecular change that increases calcium influx through AMPA receptors, selective in the spinal ventral gray of patients with amyotrophic lateral sclerosis. Ann Neurol. 1999;46:806-815.

29 Kwak S, Takuma H, Kanazawa I. Molecular mechanism and therapeutics of amyotrophic lateral sclerosis. San Diego, CA: Elsevier Science B.V.; 2001.

30 Li JB, Levanon EY, Yoon JK, Aach J, Xie B, Leproust E, et al. Genome-wide identification of human RNA editing sites by parallel DNA capturing and sequencing. Science. 2009;324:1210 1213.

31 Melcher T, Maas S, Herb A, Sprengel R, Seeburg P, Higuchi M. A mammalian RNA editing enzyme. Nature. 1996;379:460-464.

32 Wang Q, Khillan J, Gadue P, Nishikura K. Requirement of the RNA editing deaminase ADAR1 gene for embryonic erythropoi- esis. Science. 2000;290:1765-1768.

33 Melcher T, Maas S, Herb A, Sprengel R, Higuchi M, Seeburg PH. RED2, a brain-specific member of the RNA-specific adenosine deaminase family. J Biol Chem. 1996;271:31795-31798.

34 Chen CX, Cho DS, Wang Q, Lai F, Carter KC, Nishikura K. A third member of the RNA-specific adenosine deaminase gene family, ADAR3, contains both single- and double-stranded RNA binding domains. RNA. 2000;6:755-767.

35 Levanon EY, Hallegger M, Kinar Y, Shemesh R, Djinovic-Carugo $\mathrm{K}$, Rechavi G, et al. Evolutionarily conserved human targets of adenosine to inosine RNA editing. Nucleic Acids Res. 2005;33: $1162-1168$.

36 Kwak S, Nishimoto Y, Yamashita T. Newly identified ADARmediated A-to-I editing positions as a tool for ALS research. RNA Biol. 2008;5:193-197.

37 Nishimoto Y, Yamashita T, Hideyama T, Tsuji S, Suzuki N, Kwak S. Determination of editors at the novel A-to-I editing positions. Neurosci Res. 2008;61:201-206.

38 Riedmann EM, Schopoff S, Hartner JC, Jantsch MF. Specificity of ADAR-mediated RNA editing in newly identified targets. RNA. 2008;14:1110-1118. 